\title{
Antibacterial activity and immunomodulatory effects on a bovine mammary epithelial cell line exerted by nisin A-producing Lactococcus lactis strains
}

\author{
M. Malvisi, ${ }^{*}$ M. Stuknytè,† G. Magro, ${ }^{*}$ G. Minozzi, ${ }^{*}$ A. Giardini, † I. De Noni,† and R. Piccinini*1 \\ *Department of Veterinary Science and Public Health, University of Milan, via Celoria 10, 20133 Milan, Italy \\ †Department of Food, Environmental and Nutritional Sciences (DeFENS), University of Milan, via Celoria 2, 20133 Milan, Italy \\ ¥Clerici-Sacco Group, Via Manzoni, 29/A, 22071 Cadorago, Italy
}

\section{ABSTRACT}

Twenty-nine strains of mastitis pathogens were used to study the antibacterial activity of the cell-free supernatants (CFS) of 25 strains of Lactococcus lactis ssp. lactis. Out of the tested strains, only the CFS of L. lactis LL11 and SL153 were active, inhibiting and killing most of the pathogens. By means of ultraperformance liquid chromatography/high resolution mass spectrometry, they were shown to produce nisin A, a class I bacteriocin. A variable sensitivity to nisin A-containing CFS was observed among Streptococcus uberis and Enterococcus faecalis strains. Nonetheless, Streptococcus agalactiae, Strep. uberis, and E. faecalis displayed high minimum inhibitory concentration values, reaching 384 arbitrary units/mL. Interestingly, the minimum inhibitory values and the bactericidal concentrations were almost identical among them for each of the 2 stains, LL11 and SL153. Staphylococci were, on average, less sensitive than streptococci, but the 2 CFS inhibited and killed, at different dilutions, strains of methicillin-resistant Staphylococcus aureus. The immune response to nisin A-containing CFS was tested using the bovine mammary epithelial cell line BME-UV1. Application of CFS did not damage epithelial integrity, as demonstrated by the higher activity of $\mathrm{N}$-acetyl- $\beta$-D-glucosaminidase (NAGase) and lysozyme inside the cells, in both treated and control samples. On the other hand, the increase of released NAGase after 15 to $24 \mathrm{~h}$ of treatment with LL11 or SL153 live cultures demonstrated an inflammatory response of epithelial cells. Similarly, a significantly higher lysozyme activity was detected in the cells treated with LL11 live culture confirming the stimulation of lysosomal activity. The treatment of epithelial cells with SL153 live culture induced a significant tumor necrosis factor- $\alpha$ downregulation in the cells, but did not influence IL-8

Received July 23, 2015.

Accepted November 28, 2015.

${ }^{1}$ Corresponding author: renata.piccinini@unimi.it expression. The control of tumor necrosis factor- $\alpha$ release could be an interesting approach to reduce the symptoms linked to clinical intramammary infections. Due to their antibacterial activity and to the stimulation of lysosomal activity of mammary epithelial cells, the L. lactis strains SL153 and LL11 could be of interest for the development of alternative intramammary treatments to control cow mastitis.

Key words: dairy cow mastitis, Lactococcus lactis, nisin A, mammary epithelial cells, ultra-performance liquid chromatography/high resolution mass spectrometry

\section{INTRODUCTION}

Mastitis still represent one of the major cause of economic losses in dairy herds due to reduction of milk production and quality (Geary et al., 2014), premature culling (Heikkilä et al., 2012), and the costs related to antibiotic therapy and waste milk during the withholding period after antibiotic treatment. Also, calf feeding with discarded milk, either raw or pasteurized, raises the risk of selecting resistant fecal bacteria (Aust et al., 2013). The presence of antibiotic residues in milk can also inhibit the starter cultures used for manufacturing of cheese and yogurt (Heap, 1982). For these reasons, public opinion has shifted toward reduction in the use of antibiotics in veterinary field, and researchers are interested in finding new alternative approaches for treatment and control of mastitis.

Some strains of lactic acid bacteria (LAB) are known to produce bacteriocins, which are ribosomally synthesized secreted peptides exerting antimicrobial activity either in the same species (narrow spectrum) or across the genera (broad spectrum; Balciunas et al., 2013). Bacteria resist their own bacteriocins by producing specific proteins that provide sequestration or competition for bacterial receptors or pump bacteriocins out through the bacterial membrane (Cotter et al., 2005). Among producer strains, LAB are the most investigated because they are allowed to be present in foods, being approved as generally recognized as safe 
organisms by the US Food and Drug Administration (Gaynor et al., 2006). At present, the application to the mammary gland of viable LAB cultures or bacteriocins is under investigation. Bouchard et al. (2013) demonstrated the in vitro ability of Lactobacillus casei strains to prevent Staphylococcus aureus adhesion and internalization in MAC-T bovine mammary epithelial cells. Other recent studies highlighted the efficacy of nisin A, a class I bacteriocin produced by Lactococcus lactis ssp. lactis, as a valid tool for the treatment of clinical or subclinical mastitis (Cao et al., 2007; Wu et al., 2007; Klostermann et al., 2008). Beecher et al. (2009) demonstrated that the administration of a live culture of $L$. lactis into the bovine mammary gland stimulated the innate immune response, as shown by higher proinflammatory cytokine expression by milk somatic cells in treated quarters in comparison with controls. To the best of our knowledge, studies regarding the interaction between LAB or bacteriocins and the mammary epithelial cells are still lacking in the literature. Therefore, the aims of the present study were (1) to evaluate the antibacterial activity of the cellfree culture supernatant (CFS) of 25 L. lactis strains against mastitis pathogens; (2) to identify the produced bacteriocins by ultra-performance liquid chromatography/high resolution mass spectrometry (UPLC/HRMS); and (3) to investigate the ability of the active $L$. lactis live cultures and the derived CFS to modulate the immune response of mammary epithelial cells.

\section{MATERIALS AND METHODS}

\section{Bacterial Strains}

Twenty-nine strains of mastitis pathogens were selected from the culture collection of the Department of Veterinary Science and Public Health (University of Milan, Milan, Italy): Streptococcus agalactiae (MB343, MB386, MB422); Streptococcus dysgalactiae (MB280, MB324); Streptococcus uberis (MB300, MB705, MB707); Enterococcus faecalis (MB330, MB561, MB562, MB706); Staphylococcus aureus (MB221, MB254, MB351, MB390, MB439, MB501, MB512, MB535, MB543, MB781, MB786, MB798), including methicillin-resistant Staph. aureus (MRSA; MB508, MB628); and Staphylococcus chromogenes (MB307, MB309, MB316).

Bacterial isolates had been collected from quarter milk samples of dairy cows during mastitis-control programs. All strains were from subclinical IMI, 4 from clinical mastitis (MB280, MB705, MB535, and MB798) and 1 from a quarter after antibiotic treatment (MB707). Bacteriological analysis of milk and bacterial colony identification was performed according Hogan et al. (1999). Species identification was confirmed by API System (Rapid ID 32 Strep, bioMérieux, Marcyl'Étoile, France). Antibiotic sensitivity of each strain was tested by Kirby-Bauer disk diffusion method (CLSI, 2008). The drugs mainly used in the treatment of clinical or subclinical bovine mastitis (penicillin, ampicillin, amoxicillin/clavulanic acid, oxacillin, first-, third-, and fourth-generation cephalosporins, norfloxacin, rifaximin, tylosin, kanamycin, tiamphenicol, and sulfamethoxazole/trimethoprim) were tested. All isolates were stored at $-80^{\circ} \mathrm{C}$ in Microbank Bacterial Preservation System (Thermo Fisher Scientific Inc., Waltham, MA). Before use, the thawed isolates were cultured on bovine blood agar plates (5\% of blood, Oxoid, Basingstoke, UK) and thereafter grown in brain heart infusion (BHI) broth (Oxoid) for $24 \mathrm{~h}$ at $37^{\circ} \mathrm{C}$.

Twenty-five strains of L. lactis from the collection of Clerici-Sacco Group (Cadorago, Italy) were tested for antibacterial activity. They were maintained on de Man, Rogosa, Sharpe agar (Difco, Bordeaux, France) at $4^{\circ} \mathrm{C}$ until use.

\section{Partial Purification of Antibacterial Molecules}

Partial purification of antibacterial molecules produced by the strains of L. lactis, cultivated in de Man, Rogosa, Sharpe broth, was performed by the adsorption-desorption method as described by Yang et al. (1992) and Kaur et al. (2013). The release of bacteriocins from the cell wall is known to be complete at $\mathrm{pH} 3.0$, and after addition of lactic acid, the broth cultures were centrifuged at 29,000 $\times g$ for $15 \mathrm{~min}$ at room temperature and adjusted to $\mathrm{pH}$ 7.0. Finally, CFS were sterilized by filtration through $0.22-\mu \mathrm{m}$ pore size cellulose acetate filter and stored at $-80^{\circ} \mathrm{C}$ until use. The crude or partially purified CFS were subsequently fractionated by UF through a 1-kDa cut-off membrane (Merck Millipore, Darmstadt, Germany) and tested for antibacterial activity.

\section{Antibacterial Activity of L. lactis Strains}

Antibacterial activity of CFS was tested using the MIC assay against each mastitis pathogen isolate according to Clinical and Laboratory Standards Institute guidelines (CLSI, 2008). Serial 2-fold dilutions of each CFS were performed in $100 \mu \mathrm{L}$ of BHI broth supplemented with 5\% fetal calf serum (Gibco, Thermo Fisher Scientific) in 96-well microplates. The antimicrobial activity of each CFS was expressed as arbitrary units (AU) per milliliter, with 1 AU defined as the reciprocal of the highest dilution that completely inhibited bacterial growth. The turbidity in the wells containing the CFS was compared with the turbidity 
of the control wells, as detected by the unaided eye, in accordance with CLSI procedures (CLSI, 2008). To test bactericidal effect of the CFS, the minimum bactericidal concentration (MBC) was assayed, plating 10 $\mu \mathrm{L}$ of the dilution representing the MIC endpoint and of 2 more concentrated dilutions and then counting the colonies of growth. The MBC was defined as the lowest concentration showing $\geq 99 \%$ killing (CLSI, 2008).

\section{SDS-PAGE of CFS of L. lactis LL11 and SL153}

After UF at $1 \mathrm{kDa}$, the permeates and the retentates of crude CFS and partially purified CFS were mixed with SDS-PAGE native sample buffer (Bio-Rad Laboratories, Hercules, CA). Separation was performed on a $15 \%$ polyacrylamide gel in Tris-glycine-SDS buffer on SE 250 mini-vertical gel electrophoresis system (Hoefer Inc., Holliston, MA). PageRuler Plus Prestained Protein Ladder (10-250 kDa; Thermo Fisher Scientific) and Spectra Multicolor Low Range Protein Ladder (1.7-40 $\mathrm{kDa}$; Thermo Fisher Scientific) were used as protein molecular weight markers. The electrophoresis was run at $23^{\circ} \mathrm{C}$ and $50 \mathrm{~V}$ for the first $0.5 \mathrm{~h}$ and then at $100 \mathrm{~V}$ for $2 \mathrm{~h}$. Gels were stained with Coomassie brilliant blue G-250. The molecular weights of protein bands were estimated by calculating the relative migration distance (rf) values as described by Hames (1998).

For the antibacterial activity test, unstained polyacrylamide gels were fixed, washed (with milliQ-treated water (Merck Millipore) for $2 \mathrm{~h}$ at $25^{\circ} \mathrm{C}$ in slight agitation changing water every $15 \mathrm{~min}$ ), aseptically placed on soft agar (1\% BHI agar supplemented with $5 \%$ of fetal calf serum), and overlaid with the same medium inoculated with $10^{6} \mathrm{cfu} / \mathrm{mL}$ of Strep. agalactiae MB386. This strain was chosen as an indicator of antibacterial activity based on the MIC results. The plates were incubated at $37^{\circ} \mathrm{C}$ for 18 to $24 \mathrm{~h}$ and the inhibition zone of growth was evaluated.

\section{Separation and Identification of Antimicrobial Molecules}

The UF retentates of the partially purified CFS were analyzed by UPLC using an Acquity separation module (Waters, Milford, MA) with a photo diode array e $\lambda$ detector (Waters). The UPLC was coupled to a highresolution Q Exactive MS (Thermo Scientific, San Jose, $\mathrm{CA}$ ) through an electrospray ionization source. Samples were separated on an Aeris Widepore XB-C4 column $(2.1 \times 150 \mathrm{~mm}, 3.6 \mu \mathrm{m}$; Phenomenex, Torrance, CA) kept at $40^{\circ} \mathrm{C}$. The eluents were $0.1 \%$ trifluoroacetic acid in milliQ-treated water (solvent A) and $0.1 \%$ trifluoroacetic acid in acetonitrile (solvent B). The UPLC sepa- ration was performed by using a linear elution gradient (10\% to $55 \%$ of solvent $\mathrm{B}$ in $13.7 \mathrm{~min}$ ) at a flow rate of $0.2 \mathrm{~mL} / \mathrm{min}$. Proteins in the eluate were detected at $210 \mathrm{~nm}$ and subsequently analyzed by HR-MS using full scan analysis in the range of 300 to $2,000 \mathrm{~m} / z$. The resolution was set at $35 \mathrm{~K}$; the automatic gain control (AGC) target was $5 \times 10^{5}$. The maximum ion injection time was $100 \mathrm{~ms}$. The MS data were automatically processed using Xcalibur 3.0 software (Thermo Scientific), and protein mass deconvolution was performed using Xtract software (Thermo Scientific).

\section{Challenge of Bovine Mammary Epithelial Cell Line with CFS or Live L. lactis}

The continuous cell line of bovine mammary epithelial cells, BME-UV1, was grown to confluence in 6-well plates (Falcon Becton Dickinson Labware, Franklin Lakes, NJ) for $58 \mathrm{~h}$, as described by Zavizion et al. (1996). The cells were washed twice with Hanks' balanced salts solution (Sigma-Aldrich, St. Louis, MO). Complete medium without fetal calf serum was added before the challenge with CFS or live lactococcal cultures to avoid possible interference of the serum with the enzyme activity; the experiment was performed in duplicate.

Two L. lactis strains (LL11 and SL153) were incubated in RPMI-1640 medium for $48 \mathrm{~h}$ and the derived CFS were assayed with the MIC test to confirm the antibacterial activity. The CFS were then added to BME-UV1 cell-culture to a final concentration of $10 \%$ in fetal calf serum-free medium. Analogously, $30 \mu \mathrm{L}$ of a suspension $\left(10^{4} \mathrm{cfu} / \mathrm{mL}\right)$ of each lactococcal live culture were added to distinct wells, and after 4, 8, 15 , and $24 \mathrm{~h}$ of stimulation both culture medium and epithelial cells were collected and stored separately. Aliquots of $3 \times 10^{6}$ BME-UV1 cells were suspended in RNAlater (Sigma-Aldrich) and stored at $-80^{\circ} \mathrm{C}$ until RNA extraction, whereas culture medium was frozen at $-20^{\circ} \mathrm{C}$.

\section{Detection of Enzyme Activity and Cytokine Expression}

Culture medium was tested for the amount of antibacterial enzymes typically involved in the mammary innate immune response; that is, N-acetyl- $\beta$ D-glucosaminidase (NAGase) and lysozyme (LZ). Epithelial cells were assayed for both enzymes activities and for proinflammatory cytokines [tumor necrosis factor (TNF)- $\alpha$ and IL-8] expression. Both NAGase and LZ were quantified in duplicate on a microplate fluorometer (Fluoroskan Ascent, Thermo Fisher Scien- 
tific) using fluorescence-based procedures, as previously described (Kitchen et al., 1978; Pilla et al., 2010).

Total RNA was extracted using Illustra Mini RNA isolation kit (GE Healthcare, Little Chalfont, UK) according to manufacturer's instructions; RNA quantification and purity was estimated by a spectrophotometer ND-100 (Nanodrop Technologies, Wilmington, DE). The RNA was reverse transcribed using QuantiTect Reverse Transcription Kit (Qiagen, Venlo, the Netherlands) and quantitative real-time PCR was performed in triplicate, using EvaGreen fluorescent detection system and the Eco Real-Time PCR System (Illumina Inc., San Diego, CA). The GAPDH gene was selected as housekeeping gene for its stability, as demonstrated in a recent research study on the validation of reference genes to be applied in bovine mastitis research (Bougarn et al., 2011). Primer sequences for GAPDH and $T N F-\alpha$ genes were previously published by Tomasinsig et al. (2010); the primers for $I L-8$ were from Günther et al. (2010). Oligonucleotide concentration was $100 \mathrm{n} M$ for $G A P D H$ and $T N F-\alpha$, or $200 \mathrm{n} M$ for $I L$ 8. The PCR amplifications were performed using the following conditions: $\mathrm{Taq}$ polymerase activation at $95^{\circ} \mathrm{C}$ for $3 \mathrm{~min}, 45$ cycles of denaturation at $95^{\circ} \mathrm{C}$ for $10 \mathrm{~s}$, and annealing or extension at $62(T N F-\alpha)$ or $59^{\circ} \mathrm{C}(I L-$ 8) for $15 \mathrm{~s}$. The specificity of the reaction was verified postamplification by melt curve analysis. For relative quantification of mRNA, the cycle threshold values of the target gene transcripts were normalized against the reference gene $G A P D H$, and the results were expressed as normalized fold expression relative to the control (not stimulated cells).

\section{Statistical Analysis}

The statistical analysis of the data was performed using the software SPSS Statistics (version 21.0; IBM, Armonk, NY). For the analysis, the results of NAGase and LZ activity in the first 2 time points ( 4 and $8 \mathrm{~h}$ ) were gathered and considered as early observations; the other time points ( 15 and $24 \mathrm{~h}$ ) were considered as late observations. For proinflammatory cytokine mRNA, only the 4-h observations were considered as early ones, because it was expressed in the first hours after stimulation. Means were compared by 2 -way ANOVA and Scheffé post-hoc test. Time and treatment variables were used as main effects, and NAGase, LZ, and cytokine expression as the dependent variables. Oneway ANOVA was applied when the time variable was not significant and to analyze the differences between intracellular and extracellular localization of enzymes. Results were considered as statistically significant at $P$-values $<0.05$.

\section{RESULTS}

Antibiotic sensitivity patterns of mastitis isolates, determined by agar plate diffusion, showed that all strains were resistant to at least 1 of the tested antibiotics (Table 1). All Strep. agalactiae strains were resistant to oxacillin and most of them were also resistant to rifaximin and macrolides. Streptococcus dysgalactiae and Strep. uberis were mostly resistant to macrolides but susceptible to the other tested drugs. On the contrary, E. faecalis evidenced a broad resistance to oxacillin, penicillin, macrolides, and tiamphenicol. When considering Staph. aureus, most strains were resistant to penicillin and ampicillin, but sensitive to the other drugs. Both MRSA were also resistant to sulfamethoxazole/trimethoprim and, obviously, to oxacillin.

Out of 25 L. lactis strains, only the CFS of LL11 and SL153 were active against mastitis pathogens (Table 2). Nevertheless, a variable sensitivity, expressed as both MIC and MBC, was observed not only among species, but also among different strains belonging to the same bacterial species (Table 2). Identification of the antibacterial molecules produced by these 2 L. lactis strains was performed in partially purified CFS obtained by the adsorption-desorption method as described in the Materials and Methods. The activity of these partially purified CFS against the indicator strain (Strep. agalactiae MB386) was maintained, indicating that the antimicrobial compound was successfully recovered. After UF at $1 \mathrm{kDa}$, the permeates of the partially purified LL11 and SL153 CFS lost their antibacterial activity, contrary to the 2 UF retentates that were further subjected to the SDS-PAGE analysis. For both CFS, a narrow protein band at about $4 \mathrm{kDa}$ was revealed (Supplementary Figure S1; http://dx.doi.org/10.3168/ jds.2015-10161). The retentates of partially purified CFS of L. lactis LL11 and SL153 were subsequently fractionated by UPLC/HR-MS. The chromatograms showed the presence of a major peak at 11.8 min retention time for both CFS (Supplementary Figure S2A and B; http://dx.doi.org/10.3168/jds.2015-10161). The accurate mass of the molecules corresponding to both chromatographic peaks was 3,353.55 Da (Supplementary Figure S3; http://dx.doi.org/10.3168/jds.201510161). Accordingly, the molecule was assigned to the peptide nisin A (Piper et al., 2011). Further UPLC/ HR-MS analysis of standard nisin A (Sigma-Aldrich) confirmed this assignment (Supplementary Figure $\mathrm{S} 2 \mathrm{C})$.

The live L. lactis cultures and the derived CFS were further investigated for their ability to modulate the immune response of mammary epithelial cells. To this purpose, the stabilized line of bovine mammary epithelial 


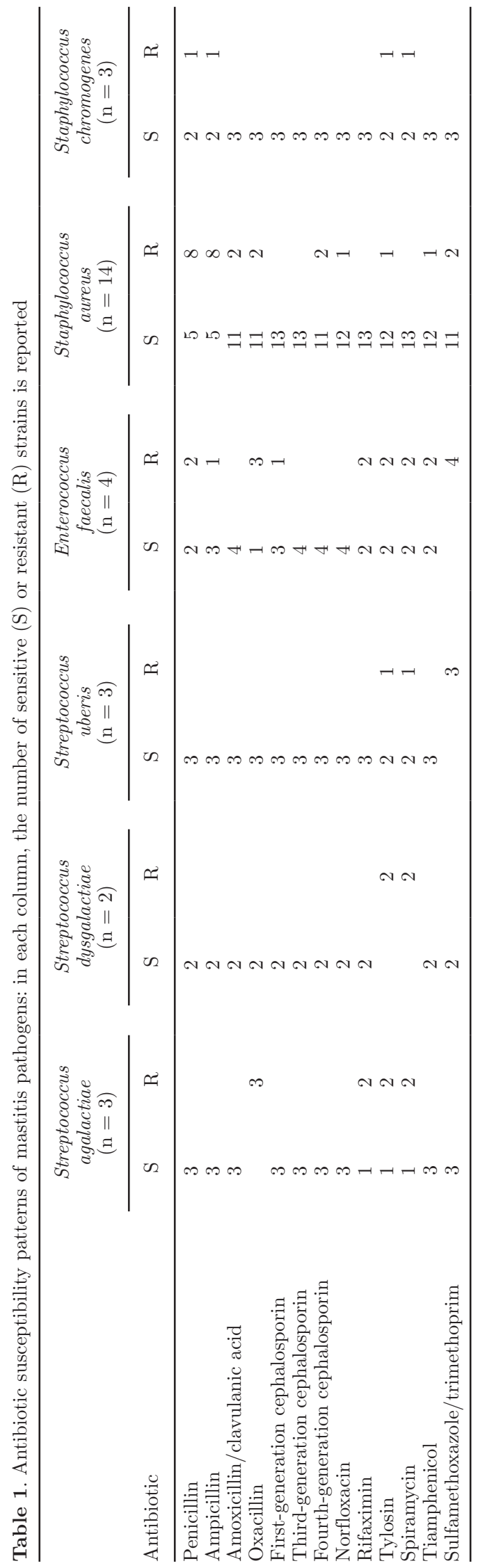

cells BME-UV1 was used as an in vitro model because it produces proinflammatory cytokines and antibacterial molecules upon stimulation (Tomasinsig et al., 2010). The NAGase and LZ activities were investigated in both the intracellular and extracellular compartments. Significant differences between the compartments were observed in controls for both NAGase and LZ $(P \leq$ 0.001), with higher amounts of the enzymes stored in the cells. When considering NAGase the figure did not change in all treated samples, whereas for LZ the intracellular activity remained significantly higher only in the samples treated with L. lactis SL153 bacteriocins or live culture. After the application of LL11, an increase of released enzyme was detected, but no decrease in the intracellular activity (Figure 1). Time and treatment (CFS or live cultures of L. lactis LL11 and SL153) did not significantly influence the intracellular NAGase and LZ activities during $24 \mathrm{~h}$ of incubation. In the extracellular compartment, in the early observations, NAGase activity was higher when the cells were treated with the live LL11 strain, rather than with its CFS $(P=0.049)$. After 15 to $24 \mathrm{~h}$ of incubation, the cells treated with LL11 or SL153 live cultures showed a 5-fold increase in the release of NAGase $(P=0.002$ and $P=0.001$, respectively) in comparison with both bacteriocin-treated cells and controls (Figure 2).

A completely different activity pattern described the extracellular LZ. In the early observations, LZ activity showed a significant increase when cells were treated with CFS but not with live cultures of LL11 or SL153 strains $(P=0.02$ and $P=0.001$, respectively). Thereafter, in the late observations, a maximum LZ activity was detected in of BME-UV1 cells stimulated with LL11 live culture $(P<0.001$; Figure 3$)$.

Overall, the expression of proinflammatory cytokines by BME-UV1 cells in response to nisin A-containing CFS or live lactococcal cultures was similar to that of untreated cells (Figure 4). The only difference $(P=$ 0.047) was observed with SL153 culture, which caused a marked decrease in TNF- $\alpha$ expression in comparison with the control. The measurements at different time points showed considerably stable values throughout the 24-h observations. The only exception, though not significant, was the relative expression of IL-8, which showed a 7-time increase over the untreated cells at 15 h post-treatment with LL11 culture.

\section{DISCUSSION}

Even though a variable sensitivity to nisin A-containing CFS was observed among Strep. uberis and E. faecalis strains, Strep. agalactiae, Strep. uberis, and E. faecalis displayed high MIC values (i.e., high sensitivity to $\mathrm{CFS}$ ) reaching $384 \mathrm{AU} / \mathrm{mL}$. This result worth noting 
when considering the pattern of antibiotic resistance demonstrated by the tested strains. Indeed, most Strep. agalactiae, Strep. dysgalactiae, E. faecalis, and Staph. aureus strains showed multiple resistance to the drugs generally used in the treatment of dairy cow IMI. Interestingly, the MIC values and the bactericidal concentrations were almost identical among them for each of the 2 stains, LL11 and SL153. Such a finding is explained by the mode of action of class I bacteriocins. Nisin A forms a complex with the cell wall precursor lipid II, thus inhibiting the biosynthesis of the cell wall. After aggregation, the complexes include other peptides and form a pore in the bacterial membrane, thus causing the death of the microorganism (Moll et al., 1999). In our study, staphylococci were less sensitive than streptococci, on average, but the 2 tested MRSA strains were inhibited or killed at a 1:1 or 1:4 dilution, respectively. The result of interest because these microorganisms represent a major threat to human health due to the development of multiple antimicrobial resistance.

On the side of mammary cells, the application of nisin A-containing CFS or LL11 and SL153 live cultures did not damage epithelial integrity, as demonstrated by NAGase and LZ release. The amount of intracellular enzymes was significantly higher than that of released enzymes, both in controls and in treated cells. The unique exception was the increase in the secretion of LZ when LL11 was applied, even if no decrease in the intracellular activity was detected; consequently, the significance between the LZ activity in the 2 compartments was lost. The enzymes are physiologically produced and stored in the cells and are secreted when an inflammatory stimulus occurs (Kitchen et al., 1978; Ebling et al., 2001). Conversely, the noticeable increase of released NAGase after 15 to $24 \mathrm{~h}$ of treatment with LL11 or SL153 live cultures demonstrated an inflammatory response by epithelial cells. The enzyme is usually considered an indicator of dairy cow mammary inflammation and immunity response activation, as its amount increases in milk from clinical and subclinical mastitis (Åkerstedt et al., 2011). Similarly, the significantly higher LZ activity detected in the cells treated with LL11 live culture confirmed the stimulation of lysosomal activity, whereas intracellular enzyme remained stable. It is well known that the activity of NAGase and LZ increase during an inflammation (Sarikaya et al., 2006), and that the content of both enzymes in healthy mammary quarters is not correlated with milk SCC, but rather to age and lactation stage of cows (Piccinini et al., 2007).

Table 2. Minimum inhibitory concentration and minimum bactericidal concentration (MBC) values showed by Lactococcus lactis LL11 and SL153 culture cell-free supernatants against mastitis pathogens, expressed as arbitrary units $/ \mathrm{mL}(\mathrm{AU} / \mathrm{mL})$

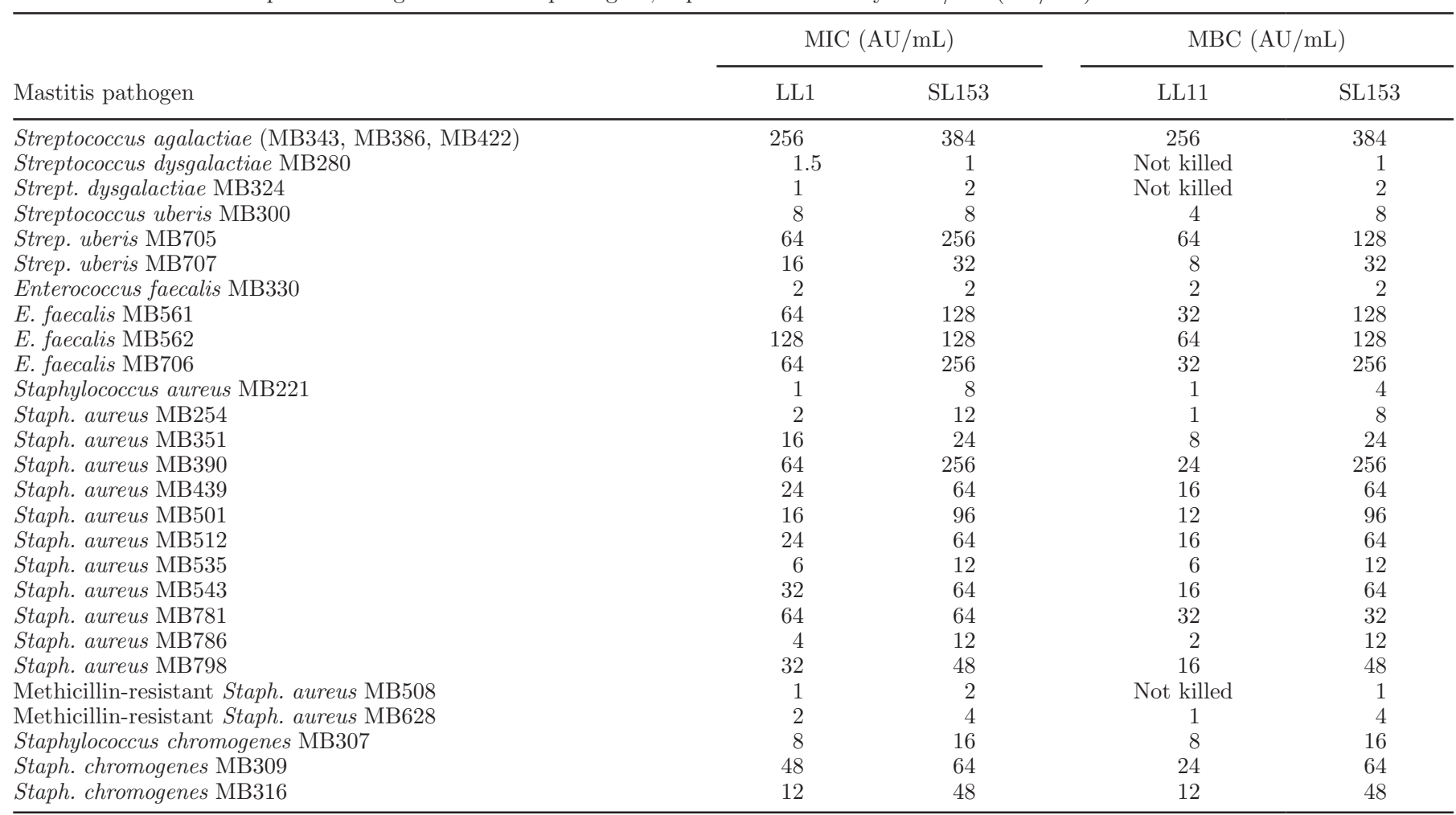


As further demonstrated by Bruckmaier (2005), udder tissues play a pivotal role as a primary source of innate immunity factors, expressing proinflammatory cytokines and antibacterial enzymes after challenge with Escherichia coli LPS. The treatment with SL153 live culture induced a significant TNF- $\alpha$ mRNA expression downregulation in the cells, but did not influence IL-8 expression. Although proinflammatory cytokines stimulate the host innate immune defenses, which are fundamental against infections, TNF- $\alpha$ causes the typical signs of clinical inflammation. Therefore, the control of TNF- $\alpha$ release could be an interesting approach to reduce the symptoms linked to clinical IMI. Furthermore, cytokines were shown to suppress lacto-

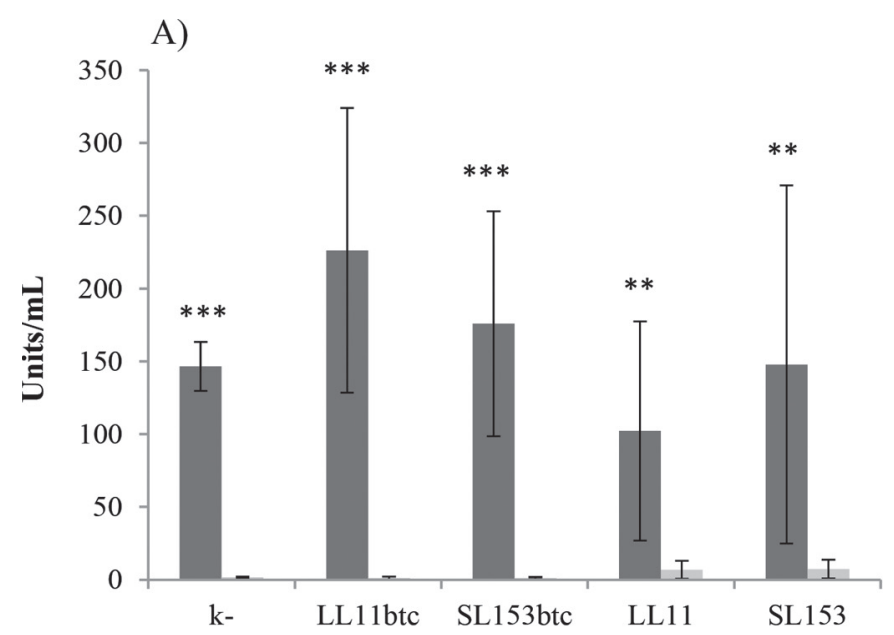

B)

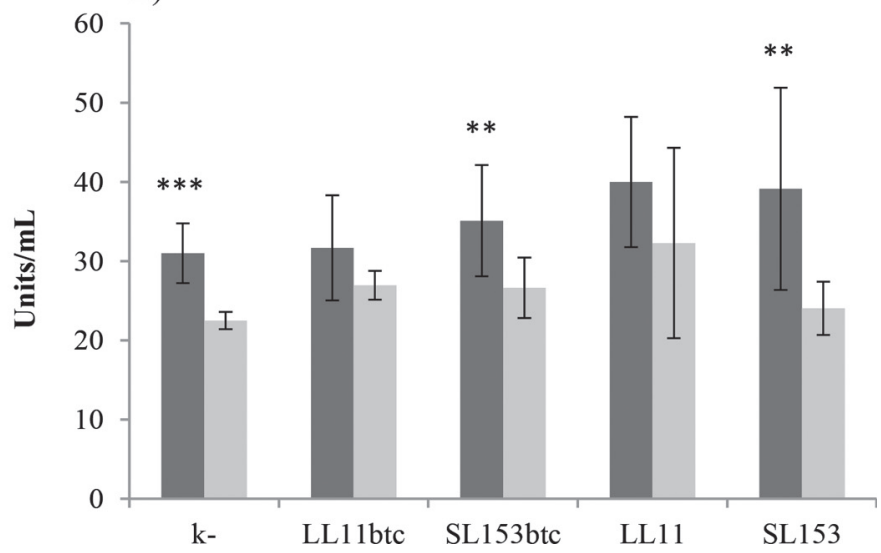

Figure 1. Intracellular activity (dark gray bars) and extracellular release (light gray bars) of N-acetyl- $\beta$-D-glucosaminidase (NAGase; A) and lysozyme (B) in untreated (k-), Lactococcus lactis LL11 or SL153 cell-free supernatant-treated (btc) or live culture-treated cells. Data are shown as means $\pm \mathrm{SD}$ of all measures throughout the 4 time points of the experiment. The mean values of NAGase and lysozyme activity were calculated from 40 measurements each, in duplicate; ${ }^{* *} P \leq 0.01$; $* * * P \leq 0.001$.

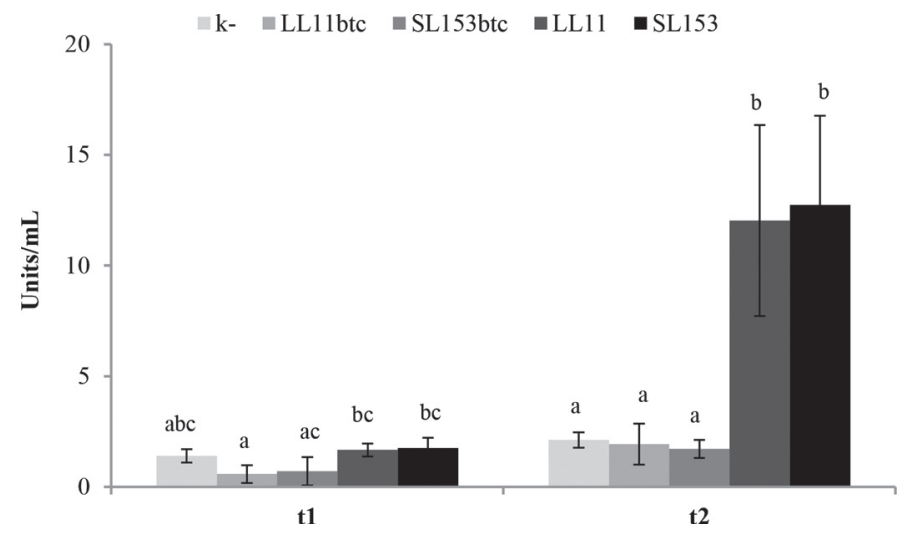

Figure 2. Extracellular N-acetyl- $\beta$-D-glucosaminidase (NAGase) activity in BME-UV1 cells treated with Lactococcus lactis LL11 or SL153 cell-free supernatant (btc), or live culture, in the early observations (t1) and late observations of the experiment (t2). The mean $( \pm$ SD $)$ values were calculated from a total of 20 measurements, in duplicate. Different letters $(\mathrm{a}-\mathrm{c})$ indicate significant difference in enzyme production between treatments $(P<0.05)$.

genic function of the glands after infusion (Alluwaimi, 2004) by an autocrine effect inhibiting the synthesis of caseins by mammary epithelial cells (Shea-Eaton et al., 2001). The mRNA expression of IL-8, the other proinflammatory cytokine considered, did not significantly change over the study, showing high variability between the 2 repetitions of the experiment. These results seem to confirm the anti-inflammatory properties of L. lactis SL153 live culture when applied onto the mammary epithelial cells.

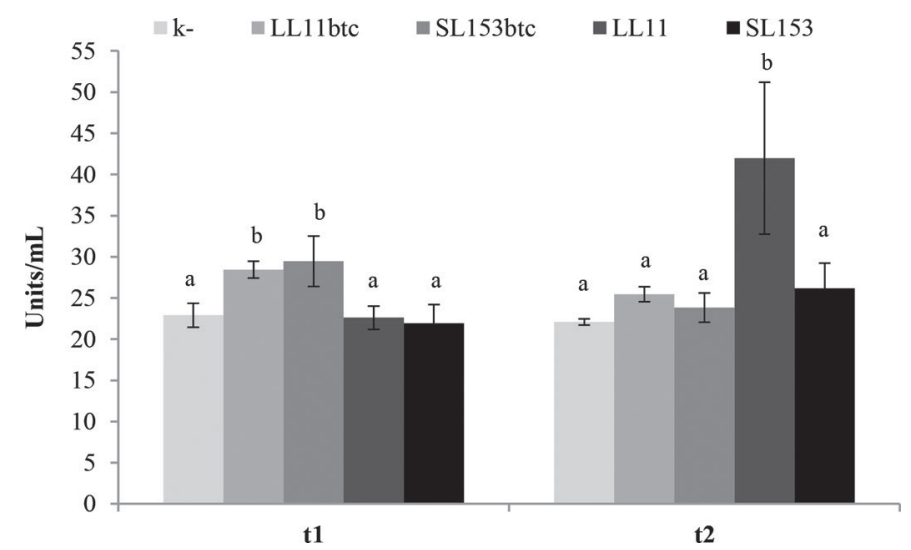

Figure 3. Extracellular lysozyme activity in BME-UV1 cells treated with Lactococcus lactis LL11 or SL153 cell-free supernatant-treated (btc), or with LL11 or SL153 live culture, in the early observations (t1) and late observations of the experiment (t2). The mean $( \pm \mathrm{SD})$ values were calculated from a total of 20 measurements, in duplicate. Different letters $(\mathrm{a}, \mathrm{b})$ indicate significant difference in enzyme production between treatments $(P<0.05)$. 


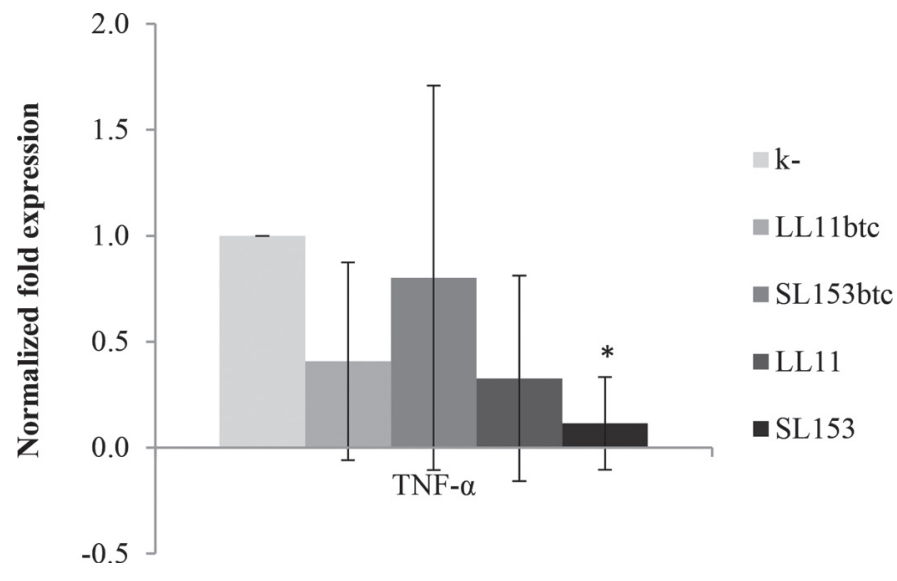

Figure 4. Normalized expression of $T N F-\alpha$ gene in BME-UV1 untreated (k-) and BME-UV1 cells treated with Lactococcus lactis LL11 or SL153 cell-free supernatant (btc), or with LL11 or SL153 live culture. Data are shown as means \pm SD of all measures throughout the 4 time points of the experiment. The mean values were calculated from a total of 20 measurements in duplicate. An asterisk $(*)$ represents a statistically significant $(P=0.047)$ difference between BME-UV1 cells treated with L. lactis SL153 live culture and the control.

\section{CONCLUSIONS}

The identification of only 2 strains with antibacterial activity, out of $25 \mathrm{LAB}$ tested, indicated that the strains applicable to the dairy cow mastitis are quite rare. Lactococcus lactis LL11 and, particularly, SL153 were of interest for the development of alternative intramammary treatments due to their antibacterial activity and to the stimulation of lysosomal enzymes of mammary epithelial cells. Indeed, the nisin A-containing CFS could kill different mastitis pathogens, including MRSA strains. Moreover, the application of the CFS to a mammary epithelial cell line stimulated the secretion of antibacterial enzymes NAGase and LZ by the cells without causing either damage to them or any adverse inflammatory reaction. Further in vivo studies are required to investigate potential clinical side effects and the cure rate of mastitis following the administration of a preparation as described above.

\section{REFERENCES}

Åkerstedt, M., M. Forsbäck, T. Larsen, and K. Svennersten-Sjaunja. 2011. Natural variation in biomarkers indicating mastitis in healthy cows. J. Dairy Res. 78:88-96.

Alluwaimi, A. M. 2004. The cytokines of bovine mammary gland: Prospects for diagnosis and therapy. Res. Vet. Sci. 77:211-222.

Aust, V., K. Knappstein, H. J. Kunz, H. Kaspar, J. Wallmann, and M. Kaske. 2013. Feeding untreated and pasteurized waste milk and bulk milk to calves: effects on calf performance, health status and antibiotic resistance of faecal bacteria. J. Anim. Physiol. Anim. Nutr. (Berl.) 97:1091-1103.

Balciunas, E. M., F. A. Castillo Martinez, S. D. Todorov, B. D. Gombossy de Melo Franco, A. Converti, and R. Pinheiro de Souza
Oliveira. 2013. Novel biotechnological applications of bacteriocins: A review. Food Contr. 32:134-142.

Beecher, C., M. Daly, D. P. Berry, K. Klostermann, J. Flynn, W. Meaney, C. Hill, T. V. McCarthy, R. P. Ross, and L. Giblin. 2009. Administration of a live culture of Lactococcus lactis DPC 3147 into the bovine mammary gland stimulates the local host immune response, particularly IL-1 $\beta$ and IL- 8 gene expression. J. Dairy Res. 76:340-348.

Bouchard, D. S., L. Rault, N. Berkova, Y. Le Loir, and S. Even. 2013. Inhibition of Staphyloccoccus aureus invasion into bovine mammary epithelial cells by contact with live Lactobacillus casei. Appl. Environ. Microbiol. 79:877-885.

Bougarn, S., P. Cunha, F. B. Gilbert, F. Meurens, and P. Rainard. 2011. Validation of candidate reference genes for normalization of quantitative $\mathrm{PCR}$ in bovine mammary epithelial cells responding to inflammatory stimuli. J. Dairy Sci. 94:2425-2430.

Bruckmaier, R. M. 2005. Gene expression of factors related to the immune reaction in response to intramammary Escherichia coli lipopolysaccharide challenge. J. Dairy Res. 72:120-124.

Cao, L. T., J. Q. Wu, F. Xie, S. H. Hu, and Y. Mo. 2007. Efficacy of nisin in treatment of clinical mastitis in lactating dairy cows. J. Dairy Sci. 90:3980-3985.

Clinical and Laboratory Standards Institute. 2008. Performance Standards for Antimicrobial Disk and Dilution Susceptibility Tests for Bacteria Isolated from Animals; Approved Standards (M31-A3). CLSI, Wayne, PA.

Cotter, P. D., C. Hill, and R. P. Ross. 2005. Bacteriocins: Developing innate immunity for food. Nat. Rev. Microbiol. 3:777-788.

Ebling, T. L., L. K. Fox, K. W. Bayles, G. A. Bohach, K. M. Byrne, W. C. Davis, W. A. Ferens, and J. K. Hillers. 2001. Bovine mammary immune response to an experimental intramammary infection with a Staphylococcus aureus strain containing a gene for staphylococcal enterotoxin C1. J. Dairy Sci. 84:2044-2050.

Gaynor, P. M., R. Bonnette, E. Garcia Jr., L. S. Kahl, and L. G. Valerio Jr. 2006. FDA's approach to the GRAS provision: A history of processes. Accessed Sep. 30, 2015. http://www.fda.gov/food/ ingredientspackaginglabeling/gras/ucm094040.htm.

Geary, U., N. Lopez-Villalobos, B. O'Brien, D. J. Garrick, and L. Shalloo. 2014. Estimating the impact of somatic cell count on the value of milk utilising parameters obtained from the published literature. J. Dairy Res. 81:223-232.

Günther, J., S. Liu, K. Esch, H. J. Schuberth, and H. M. Seyfert. 2010. Stimulated expression of TNF- $\alpha$ and IL-8, but not of lingual antimicrobial peptide reflects the concentration of pathogens contacting bovine mammary epithelial cells. Vet. Immunol. Immunopathol. 135:152-157.

Hames, B. D. 1998. Gel Electrophoresis of Proteins: A Practical Approach. 3rd ed. Oxford University Press, Oxford, UK.

Heap, H. A. 1982. Sensitivity of starter cultures to penicillin and streptomycin in bulk-starter milk. N.Z. J. Dairy Sci. Tech. 17:81-86.

Heikkilä, A. M., J. Nousiainen, and S. Pyörälä. 2012. Costs of clinical mastitis with special reference to premature culling. J. Dairy Sci. 95:139-150.

Hogan, J. S., R. N. Gonzales, R. J. Harmon, S. C. Nickerson, S. P. Oliver, J. W. Pankey, and K. L. Smith. 1999. Laboratory Handbook on Bovine Mastitis. Rev. ed. National Mastitis Council Inc. Madison WI.

Kaur, B., P. Balgir, B. Mittu, A. Chuahan, B. Kumar, and N. Garg. 2013. Antimicrobial spectrum of Anti-Gardnerella vaginalis bacteriocin producing Lactobacillus fermentum HV6b against bacterial vaginosis associated organisms. Am. J. Drug Discov. Dev. 3:91-100.

Kitchen, B. J., G. Middleton, and M. Salmon. 1978. Bovine milk $\mathrm{N}$-acetyl- $\beta$-D glucosaminidase and its significance in the detection of abnormal udder secretions. J. Dairy Res. 45:15-20.

Klostermann, K., F. Crispie, J. Flynn, R. P. Ross, C. Hill, and W. Meaney. 2008. Intramammary infusion of a live culture of Lactococcus lactis for treatment of bovine mastitis: Comparison with antibiotic treatment in field trials. J. Dairy Res. 75:365-373.

Moll, G. N., W. N. Konings, and A. J. Driessen. 1999. Bacteriocins: Mechanism of membrane insertion and pore formation. Antonie van Leeuwenhoek 76:185-198. 
Piccinini, R., E. Binda, and M. Belotti. 2007. Evaluation of milk components during whole lactation in healthy quarters. J. Dairy Res. $74: 226-232$.

Pilla, R., V. Daprà, A. Zecconi, and R. Piccinini. 2010. Hygienic and health characteristics of donkey milk during a follow-up study. J. Dairy Res. 77:392-397.

Piper, C., C. Hill, P. D. Cotter, and R. P. Ross. 2011. Bioengineering of a Nisin A-producing Lactococcus lactis to create isogenic strains producing the natural variants Nisin F, Q and Z. Microb. Biotechnol. 4:375-382.

Sarikaya, H., G. Schlamberger, H. H. D. Meyer, and R. M. Bruckmaier. 2006. Leukocyte populations and mRNA expression of inflammatory factors in quarter milk fractions at different somatic cell score levels in dairy cows. J. Dairy Sci. 89:2479-2486.

Shea-Eaton, W. K., P. P. Lee, and M. M. Ip. 2001. Regulation of milk protein gene expression in normal mammary epithelial cells by tumor necrosis factor. Endocrinology 142:2558-2568.
Tomasinsig, L., G. De Conti, B. Skerlavaj, R. Piccinini, M. Mazzilli, F. D'Este, A. Tossi, and M. Zanetti. 2010. Broadspectrum activity against bacterial mastitis pathogens and activation of mammary epithelial cells support a protective role of neutrophil cathelicidins in bovine mastitis. Infect. Immun. 78:1781-1788.

Wu, J., S. Hu, and L. Cao. 2007. Therapeutic effect of nisin Z on subclinical mastitis in lactating cows. Antimicrob. Agents Chemother. 51:3131-3135.

Yang, R., M. C. Johnson, and B. Ray. 1992. Novel method to extract large amounts of bacteriocins from lactic acid bacteria. Appl. Environ. Microbiol. 58:3355-3359.

Zavizion, B., M. van Duffelen, W. Schaeffer, and I. Politis. 1996. Establishment and characterization of a bovine mammary epithelia cell line with unique properties. In Vitro Cell. Dev. Biol. Anim. 32:138-148 